\title{
ethic@ @ \\ AS ANTROPOLOGIAS AUTORITÁRIAS NAS DIFERENTES FASES DO CAPITALISMO - ELABORAÇÕES A PARTIR DE ADORNO ${ }^{1}$
}

\author{
THE AUTHORITARIAN ANTHROPOLOGIES IN THE DIFFERENT \\ PHASES OF CAPITALISM - ELABORATIONS BASED ON ADORNO
}

\author{
VIRGINIA H. F. COSTA ${ }^{2}$ \\ (UFES/Brasil)
}

\begin{abstract}
RESUMO
Debateremos como Adorno emprega a psicanálise freudiana para compreender os modos hegemônicos de socialização de sujeitos, formulando diferentes antropologias autoritárias sob contextos socioeconômicos. Se, de um lado, o autoritarismo permanecerá vigente enquanto o capitalismo persistir, de outro, haveria diferentes ênfases características a serem elaboradas em momentos diversos do capitalismo - segundo as fases socioeconômicas monopolistas, do welfare state e neoliberais. Para tanto, baseamo-nos na descrição das tipologias da síndrome autoritária fornecida por Adorno, destacando diversos traços conforme as determinações sociais. Se nos anos 1940, Adorno salientou os aspectos de adequação do tipo antropológico autoritário (dotado de um eu fraco, supereu externalizado e isso desenfreado), nos anos 1960 o autor passou a reforçar o desejo de destruição como característica hegemônica do autoritário. Já relativamente ao neoliberalismo, encontramos descrições de sujeitos reindividualizados, dotados de um supereu internalizado e super-rígido, o que leva não só à tentação "miliciarizada" de se fazer "justiça com as próprias mãos", como aos "efeitos colaterais" de melancolia e depressão pela excessiva agressividade contra si mesmo.
\end{abstract}

Palavras-chave: Autoritarismo; Capitalismo; Antropologia; Tipologia.

\begin{abstract}
We will discuss how Adorno uses Freudian psychoanalysis to understand the hegemonic modes of socialization of subjects, formulating different authoritarian anthropologies under socioeconomic contexts. If, on the one hand, authoritarianism will currently remain as long as capitalism persists, on the other, there would be different characteristic emphases to be elaborated in different moments of capitalism - according to its monopolistic, welfare state and neoliberal socioeconomic phases. Therefore, we base ourselves on the description of the authoritarian syndrome typologies provided by Adorno, highlighting several traits according to social determinations. If, in the 1940s, Adorno highlighted the adequacy aspects of the authoritarian anthropological type (endowed with a weak ego, externalized superego and unrestrained id), in the 1960s the author reinforced the desire for destruction as a hegemonic characteristic of the authoritarian. Regarding neoliberalism, we find descriptions of reindividualized subjects, endowed with an internalized and super-rigid superego, which leads not
\end{abstract}


only to the "miliciarized" temptation to take "justice into their own hands", but also to the "side effects" of melancholy and depression due to excessive aggression towards oneself.

Keywords: Authoritarianism; Capitalism; Anthropology; Typology.

\section{Introdução}

Adorno produz ao longo de toda a sua obra, e sob diversos aspectos, reflexões sobre autoritarismo e fascismo. Uma premissa que perpassa tais análises é a abordagem de que o autoritarismo é objetivamente produzido pelo sistema capitalista. Isso quer dizer que ele não tende a diminuir com o progressivo desenvolvimento civilizacional, mas é parte constitutiva de tal processo socioeconômico: "Estamos convencidos de que a principal fonte de preconceito deve ser buscada em fatores sociais que são incomparavelmente mais fortes do que a 'psique' de qualquer indivíduo envolvido."3 (ADORNO, 2016, 4)

Entretanto, isso não preveniu Adorno de elaborar pesquisas cujo intuito era procurar por fatores psicológicos que tornariam o sujeito um agente mediador - como receptor e propagador - de ideologias autoritárias. Nestas análises propagandísticas e psicológicas sobre o autoritarismo - em especial nos Estudos sobre a personalidade autoritária (1950/2019) -, observamos que Adorno emprega a psicanálise freudiana não para abordar o funcionamento das mentes individuais, mas para compreender os modos hegemônicos de socialização de sujeitos. Nesse sentido, ele não se desdobrou sobre aquela parcela que se mostra específica dos indivíduos, que estaria muito mais próxima da racionalidade subjetiva. Ao contrário, ele estava interessado nos fragmentos individuais que se mostravam objetificados, alienados, irrefletidos. É no sentido de expor tal dialética entre racionalidade e irracionalidade na personalidade autoritária que Horkheimer define o tema geral do livro no prefácio:

O tema central da obra é um conceito relativamente novo o surgimento de uma espécie "antropológica" que chamamos de tipo autoritário de homem. Em contraste com o fanático de estilo mais antigo, ele parece combinar as ideias e habilidades típicas de uma sociedade altamente industrializada junto com crenças irracionais ou antirracionais. Ele é ao mesmo tempo esclarecido e supersticioso, é orgulhoso de ser individualista e tem um medo constante de não ser como todos os outros, é zeloso de sua independência e inclinado a se submeter cegamente 
ao poder e à autoridade (HORKHEIMER apud COSTA, 2019, 29).

Tal psicanálise entendida como antropologia dos sujeitos sob o capitalismo não pode ser tomada como uma natureza humana imutável, como uma essência que seria a mesma desde sempre. A antropologia do autoritário, sendo historicamente determinada, deve necessariamente se modificar segundo o avanço do capitalismo - seja em seus momentos de liberalismo, monopolismo, welfare state e neoliberalismo.

Ancoramo-nos na perspectiva de que o autoritarismo permanecerá vigente enquanto houver a persistência do capitalismo. Sendo assim, pretendemos esboçar, em nossa análise histórica, como os fatores sociais levam a uma série de formações antropológicas autoritárias, diferenciandose as ênfases características a serem elaboradas em momentos diversos do capitalismo. Para tanto, baseamo-nos na descrição das tipologias da síndrome autoritária fornecida por Adorno, destacando diferentes traços a serem ressaltados conforme as determinações sociais. A nosso ver, inclusive os desenvolvimentos sobre o autoritarismo no neoliberalismo não invalidam a tese geral dos Estudos sobre a personalidade autoritária: ao contrário, potencializa-a via outra organização metapsicológica, uma outra antropologia histórica, mas com os mesmos fins de dominação capitalista.

\section{Do capitalismo liberal ao monopolista: Autoridade e família e os Estudos sobre a personalidade autoritária}

A primeira teorização do autoritarismo na Teoria Crítica baseada em mudanças históricas do capitalismo foi produzida por Max Horkheimer e sua noção de declínio da figura paterna na passagem do liberalismo ao monopolismo socioeconômico. Segundo textos escritos nas décadas de 1930 e 1940 (baseados na formulação dos Estudos sobre autoridade e família $^{4}$, na passagem do capitalismo liberal ao monopolista, o papel dos sujeitos na esfera econômica teria se modificado, transformando a função da autoridade paterna e a formação de indivíduos por meio da instituição familiar.

Para Horkheimer, a família, assim como as demais esferas da cultura, segue os condicionantes socioeconômicos nos quais se vê inserida: "a família (...) não pode ser modificada sem uma mudança no quadro social total." (HORKHEIMER, 1982, 102) Horkheimer desenvolve uma teoria materialista da cultura, inserindo a concepção de autoridade em uma gênese socioeconômica. Segundo tal concepção, haveria formas específicas de desenvolvimento da autoridade no interior das famílias em correlação 
com as flutuações dos posicionamentos e funções do ser humano no capitalismo de forma geral. Segundo a sua análise, se, de um lado "a família se encontra em continuidade com a ideologia burguesa dominante na sociedade, por outro contém aspectos de crítica à ordem dominante: 'Não existe uma família burguesa no sentido estrito da palavra; ela é em si mesma uma contradição do princípio individualista, uma contradição todavia necessária'"' (MATOS, 1985, 174-5).

A dupla função contraditória da autoridade familiar, centralizada na figura paterna, seria a de possibilitar, de um lado, o desenvolvimento de faculdades humanas relacionadas à experiência formativa, uma vez que a autoridade pode agir no interesse de seus subordinados. Tal situação se aplica à autoridade familiar que socializa indivíduos por meio de uma "boa educação". Assim, a "autoridade enquanto dependência aceita pode implicar uma relação que favorece o progresso, estando no interesse de todas as partes e favorecendo o desenvolvimento dos poderes humanos." (HORKHEIMER, 1982, 70) A esta faceta da função formativa dos pais chamamos progressista. No entanto, de outro lado, a autoridade pode contribuir para a inércia psíquica de seus subjugados, o que leva à "continuação de condições de vida constrangedoras e indignas." (HORKHEIMER, 1982, 71) Isso ocorre quando há interesses egoístas e exploratórios na relação entre autoridade familiar e dependentes, o que leva a uma regressão na procura por felicidade e no desenvolvimento da autonomia daqueles orientados pela autoridade. A esta outra faceta da função formativa dos pais, chamamos, então, regressiva.

Historicamente, contudo, na passagem para o capitalismo monopolista, teria ocorrido o fim da competição individual no mercado liberal, de modo que a organização social e leis econômicas tornaram-se princípios estranhos aos indivíduos - frente aos quais estes, em situação de "desamparo", devem somente se adaptar:

No coração da liberdade e da aparente originalidade do empreendedor (...) há adaptação a uma situação social em que a humanidade não controla seu próprio destino, sujeição a um processo sem propósito em vez de sua regulação racional, dependência em uma condição irracional de sociedade segundo a qual se deve tentar lucrar ao invés de moldá-la em sua totalidade (HORKHEIMER, 1982, 82).

Dentre as consequências diante da mudança da instituição familiar na época do capitalismo monopolista, podemos dizer que a autoridade patriarcal familiar, agora em situação de desamparo promovida pela condição socioeconômica, se vê obrigada a adaptar-se a um destino 
incontrolável e incompreensível, perdendo seu papel ativo na sociedade. A coerção social na formação individual no capitalismo monopolista passa a impor com extrema rigidez uma determinação que direciona os indivíduos a "aceitar as condições existentes de trabalho" (HORKHEIMER, 1982, 57), caso contrário, passariam fome.

Nesse sentido, "os homens no poder deixaram de agir como representantes da autoridade celestial e terrestre e consequentemente se tornaram meras funções das leis inerentes ao seu poder." (HORKHEIMER, 1982 , 82) Trata-se da teoria do declínio da autoridade paterna.

Onde a família ainda é uma comunidade produtiva, o chefe da família é imediatamente visto em sua realização social produtiva. Mas na família que se reduziu a uma comunidade de consumidores, sua posição é adquirida essencialmente pelo dinheiro que ele traz e envolve todas as consequências mais importantes para a sua família (HORKHEIMER, 1982, 108).

As características de autoridade socialmente difundida passam a seguir somente os determinantes do status quo capitalista que, em nível social mais amplo que a família, mostra ser uma cultura reificada, despersonalizada, uma facticidade econômica incompreensível e irracional. Com tal declínio, o poder de autoridade teria passado do pai para figuras e instituições sociais externas à família - como organizações políticas, educação escolar, figuras midiáticas. Se antes a relação entre a psique e o social era pessoalmente mediada pelas figuras familiares, a partir do capitalismo monopolista tal relação passa a ser produzida por determinação direta de autoridades sociais sobre o indivíduo:

o vácuo criado pela diminuição da autoridade do pai e sua ausência no lar foi cada vez mais preenchido pelas forças da sociedade civil, quebrando assim 0 isolamento da esfera privada. A escola, o grupo de semelhantes e acima de tudo a indústria cultural passaram a desempenhar um papel progressivamente maior na socialização da criança (WHITEBOOK, 1996, 138).

Assim, a posição mediadora entre os indivíduos em formação e os condicionantes sociais exercida anteriormente pela família perde força, não mais havendo, com isso, a possibilidade de um desenvolvimento crítico e autônomo de indivíduos frente às figuras e instituições sociais. Em outras palavras, a autoridade familiar passou a não mais formar indivíduos 
conforme a sua anterior função progressista, estabelecendo exclusivamente a conduta regressiva e adaptativa a seus subordinados. Para Horkheimer, então, a formação orientada somente para a obediência e submissão à autoridade, e não para a autonomia, tornou-se a função exclusiva da família na socialização de indivíduos na fase do capitalismo monopolista.

É partindo de tal base conceitual que Adorno produz, juntamente com a equipe de Berkeley, os Estudos sobre a personalidade autoritária. Ao longo dos anos 1940, momento em que a pesquisa foi produzida, Adorno organiza sua análise baseada principalmente na teoria freudiana. Para tanto, ele parte do seguinte pensamento: se a gênese do fascismo é objetiva, relacionada aos interesses do capitalismo, e se a vinculação do fascismo com a realidade objetiva é tão fraca, de modo que a sua substância se encontra na propaganda ideológica autoritária, nota-se que a finalidade geral do fascismo seria justamente impactar o inconsciente subjetivo. Então, a gênese fascista é social, mas o objetivo substancial de mobilização propagandística é psíquico. Logo, o objetivo geral da pesquisa seria diagnosticar o motivo de alguns sujeitos cederem mais facilmente do que outros aos apelos ideológicos autoritários produzidos pelo capitalismo.

Uma vez que o capitalismo se utiliza de sistemas políticos democráticos para ascender ao poder e, por vezes, se manter vigente, ele faz com que estes permaneçam pseudodemocráticos, a democracia nunca se realizando plenamente. Vemos, então, coexistirem simultaneamente em uma mesma estrutura social, e, por consequência, nas estruturas psíquicas, conflitos entre os estereótipos de preconceito culturalmente produzidos e "aprovados" e os valores democráticos vazios e meramente formais de igualdade, respeito e justiça. Isso nos mostra a situação de contradição e cisão psíquica dos indivíduos sob o capitalismo. Nesse sentido, é bastante frequente a presença de anomalias cognitivas nas quais as pessoas se mostram muito racionais em uma área da vida, mas, em outros domínios mais sensíveis, elas se apegam ao negacionismo científico, anti-intracepção ou anti-intelectualismo, superstições, estereotipias, projeções, personalizações, crenças. Por isso, o que encontramos na obra seria a expressão de uma racionalidade irracional em confronto ou afastamento relativamente à própria experiência. Diz Adorno:

A discrepância entre experiência e estereótipo é posta a serviço da atitude preconceituosa. O sujeito preconceituoso é vagamente consciente de que o conteúdo do estereótipo é imaginário e que sua própria experiência representa a verdade. Contudo, por razões psicológicas mais profundas, ele quer se ater ao estereótipo. Isso ele consegue transformando este último em uma expressão de sua 
personalidade e os elementos antiestereotipados em uma obrigação abstrata. Esse deslocamento é reforçado por sua convicção mais íntima de que os supostos estereótipos de tolerância não são tão fortes socialmente quanto ele faz parecer. Percebe que, enquanto parece se rebelar contra os slogans da democracia e da igualdade por razões estritamente pessoais, ele é realmente apoiado por tendências sociais poderosas. E, no entanto, afirmará, ao mesmo tempo, que age como uma pessoa sincera e independente que não se importa com o que os outros pensam (ADORNO, 2019, 285).

Para tanto, os autores procuraram encontrar quais seriam as gratificações na economia emocional e pulsional subjetivas envolvidas na identificação com ideologias autoritárias. Adorno ressalta que a propaganda fascista administra certas tendências inconscientes dos indivíduos, tornando-as ainda mais reprimidas no inconsciente. Ou seja, há algo no inconsciente dos sujeitos que é mobilizado pelo capitalismo e que não deve retornar do recalcado, precisando ser repetidamente empurrado para fora da consciência via uma propaganda fascista sem conteúdo, que afasta o sujeito da reflexão. E o que seria esse algo inconsciente?

Sendo o sistema capitalista desigual, controlador e violento, ele produz sofrimentos e mobiliza as pulsões agressivas dos indivíduos. Contudo, para que essa agressividade não se volte contra as contradições do próprio sistema capitalista que a gerou, a indústria cultural manipula a inconsciência individual, de forma que essa agressividade seria socialmente administrada e desviada para certos objetos construídos como "frágeis" pelo capitalismo - em geral relacionados a minorias, seus representantes e ideologias. Os conteúdos psíquicos inconscientes consequentes da vivência subjetiva sob o capitalismo seriam exteriorizados e manipulados socialmente, ajudando a compor um ambiente narcísico de massas no qual as ideologias produzidas pela indústria cultural amenizam os conflitos sociais, naturalizam as causas da desigualdade e transferem as contradições sociais para os "alvos corretos". A indústria cultural fomenta atitudes autoritárias ao veicular como natural certa dose de preconceito, tratando-o como um fenômeno perene, inofensivo, um mal necessário na sociedade humana. É a banalização do mal, que pode se manifestar de modos latentes, como opiniões aparentemente inofensivas, quanto como apoios a pautas políticas preconceituosas, chegando até a ações diretas de violências contra as minorias. Produz-se, então, uma personalidade autoritária fomentada pela indústria cultural para a manutenção do capitalismo. 
Mas, afinal, se o funcionamento do capitalismo leva à produção de autoritarismos, por que algumas pessoas se mostram mais autoritárias do que outras? Adorno, seguindo os desenvolvimentos de Horkheimer, analisa a instituição familiar para fornecer uma resposta, pois "é justamente a família em crise que favorece o autoritarismo e o totalitarismo". (MATOS, $1995,176)$ Em sua teoria, Adorno nos lembra que a falência da autoridade paterna não significa exatamente a extinção de sua figura, mas sim o fim de um posicionamento patriarcal produzido por si só, sem a influência direta de outras esferas extrafamiliares. A autoridade paterna torna-se apenas um meio de afirmação da esfera econômica capitalista. Isso quer dizer que a forma como a família reproduz ou não os ditames sociais capitalistas na educação infantil irá delimitar a maior ou menor adequação desta criança às determinações socioeconômicas, o que levará à formação de uma individualidade mais ou menos forte, que irá se opor a ou reproduzir o autoritarismo social vigente. De tal modo que, para Adorno, não somente a família deixou de ser responsável pela mediação entre indivíduo e sociedade, como também a mercadoria teria tomado o lugar da família nessa mediação.

Nas palavras de Adorno em 1935: "a verdadeira 'mediação' entre psicologia e sociedade não se situa na família, mas na mercadoria e no fetiche, o fetichismo é o verdadeiro correlato da reificação." Em sua carta a Leo Löwenthal em 1942, Horkheimer, por sua vez, evoca este deslocamento que finalmente foi feito: [...] "Com o declínio do eu e de sua razão reflexiva, as relações humanas se aproximam de um limite onde a dominação de todas as relações pessoais pelas relações econômicas transforma-se em uma nova forma de imediatidade, a mediação universal da vida coletiva pela mercadoria" (GENEL, 2010, 6-7).

Isso indica como os autores perceberam o avanço do capitalismo que se expandiu para todas as esferas sociais, inclusive para a família, culminando na mercantilização e objetificação de relações humanas. Nesse contexto, a posição da função paterna aparece como somente reprodutora de um modus operandi mercadológico ao enfatizar, na educação familiar, a importância de valores capitalistas como prestígio, escalonamento social, reificação e objetificação de pessoas enquanto meios de acúmulo de capital. A figura patriarcal transforma-se, então, em nada mais do que o símbolo da reificação do mundo e de pessoas ao transferir para a ordem familiar a organização mercadológica capitalista que impera em aspectos mais amplos da sociedade. 
Mas como ocorre tal processo no interior da família? Dada a perda da força da autoridade patriarcal na esfera socioeconômica, os pais teriam reforçado a rigidez educacional familiar, procurando na disciplina estrita e distância entre progenitor e filhos a tentativa de assegurar seu posicionamento de poder. Com isso, a formação infantil de sujeitos potencialmente autoritários teria sido marcada por noções de obrigação, medo e dever, e não por sentimentos ternos, seguros, amorosos e sinceros. Além disso, a criança tenderia a estender para interações sociais mais amplas a "hierarquização" vivenciada no seio familiar: deve-se respeitar os "de cima", as figuras já estabelecidas de poder econômico e político na sociedade, e descarregar a crítica nos considerados "de baixo", ou seja, nos representantes das classes e grupos de posição mais frágil na sociedade. A tendência do patriarca em falência de negar ou impedir a expressão sentimental de quaisquer fraquezas em si e na criança leva esta a recusar quaisquer sinais de fraqueza provenientes da alteridade.

Psicanaliticamente, isso quer dizer que à falência da figura patriarcal no ambiente econômico,

os pais reagiram desenvolvendo modos autoritários de agir. Mas como não havia mais uma base real para sua autoridade, não poderia haver um conflito edipiano genuíno. Em vez de internalizar a autoridade paterna e desenvolver um senso de identidade com princípios internos autônomos, os filhos permaneceram temerosos e atraídos pela autoridade externa. (CHODOROW, 1978, 189).

Para explicar esta estrutura psíquica, voltemos a Freud, precisamente à resolução do complexo de Édipo que se encontra relacionada à formação do supereu, isto é, à internalização das normas, regras e leis ensinadas no ambiente familiar. Seria mediante a identificação com a autoridade familiar que o conflito edípico poderia ter fim enquanto situação real, uma vez que os desejos sexuais e hostis não desapareceriam simplesmente, mas se perpetuariam como fantasias e assimilação das qualidades e normas dos pais, bem como dos sentimentos amorosos e agressivos ligados a eles. Seria justamente mediante esta heteronomia familiar provisória que o supereu seria formado, permitindo aos indivíduos seguirem uma lei internalizada, levando a uma autonomia na idade adulta e possível oposição crítica a normas sociais consideradas injustas por este indivíduo.

No entanto, graças às mudanças sociais provenientes do avanço do capitalismo monopolista, a formação do supereu dos mais autoritários é descrita de outra forma nos Estudos sobre a personalidade autoritária. 
Considerando que, quando crianças, eles obedeciam às normas familiares por simples imposição direta do social, sem uma mediação simbólica familiar, não teria havido compreensão do conteúdo da lei, dificultando a sua internalização e formação do supereu. Isso quer dizer que, uma vez que o autoritário só compreende a forma da lei, mas não teve os valores e conteúdos morais internalizados de modo suficiente, o lugar onde serão formulados julgamentos sobre a justiça, bondade e respeito será feito em um domínio externo a ele. O autoritário irá somente acatar e reproduzir este conteúdo imposto por meio de ideologias circulantes na cultura. Assim, se a sociedade reproduzir de modo ideológico dominante, ainda que de forma racionalizada ou camuflada, materiais sexistas, racistas, supremacistas ou qualquer outra forma autoritária, a rigidez do mais preconceituoso o levará a acatar e reproduzir tais ditames sem qualquer reflexão crítica sobre seu conteúdo. Logo, nenhuma culpa será produzida internamente ao preconceituoso, pois não haverá análise sobre a violação ou não de normas mais ou menos justas.

Tal explicação encontrada nos Estudos sobre a personalidade autoritária nos permite dizer que as funções próprias de instâncias subjetivas como que se "expandem", criando uma espécie de noção alargada do eu para fora de si operando em nível social. Essa descrição se aproxima da noção freudiana de projeção narcísica, ou seja, a formação de um ambiente que ultrapassa os limites do eu, mantendo o funcionamento regulado pelo princípio do prazer com a finalidade de evitar quaisquer conflitos e ambivalências. Como exposto no livro freudiano Psicologia das massas e análise do eu, no interior desta bolha narcísica, as reações são automatizadas, as pessoas agem sob a compulsão afirmativa de si mesmo, tal qual a racionalidade do eu identitário descrita em Dialética do Esclarecimento.

Disso decorre a forma como os mais autoritários escolheriam seus líderes e autoridades que exerceriam o papel de "supereu externo". O supereu, que deveria se comportar como uma obrigação impessoal e sublimada no interior do indivíduo, acaba, no entanto, "repersonalizado" em outra figura externa de liderança que substitui a autoridade familiar. Tal pessoa será escolhida pela filiação inconsciente com as características dos pais típicos dos mais preconceituosos, a saber, aquele que reproduz no interior da família os valores e exigências do capitalismo: fomentando a obediência pelo medo e intimidação, enfatizará a punição e condenação excessivas inclusive para os menores desvios, pregará a exclusão ou segregação de determinados grupos das camadas sociais mais frágeis, reforçará o status quo econômico-social e culturalmente já dominante, prometerá bens materiais por recompensas morais, em suma, baseará seus 
argumentos não em conclusões racionais, mas em moralismos de fachada, manipulação de ódio e agressividade:

Os sujeitos da economia pulsional são expropriados psicologicamente e essa economia é gerida mais racionalmente pela própria sociedade. A decisão que 0 indivíduo deve tomar em cada situação não precisa mais resultar de uma dolorosa dialética interna da consciência moral, da autoconservação e das pulsões. Para as pessoas na esfera profissional, as decisões são tomadas pela hierarquia que vai das associações até a administração nacional; na esfera privada, pelo esquema da cultura de massa, que desapropria seus consumidores forçados de seus últimos impulsos internos. As associações e as celebridades assumem as funções do ego e do superego, e as massas, despojadas até mesmo da aparência da personalidade, deixam-se modelar muito mais docilmente segundo os modelos $\mathrm{e}$ palavras de ordem dadas, do que os instintos pela censura interna (HORKHEIMER E ADORNO, 1985, 167).

Por meio desta "expansão" das instâncias psíquicas para o campo social, levando ao esvaziamento da individualidade autônoma, podemos notar como as instituições, principalmente em governos autoritários, acabam por explorar componentes psíquicos e inconscientes em suas organizações, como um tipo de apropriação da psicologia das massas pelos opressores. Podemos dizer que a "manipulação substituiu a internalização." (BENJAMIN, 1977, 56) Sendo a sua formação interna frágil, o autoritário tenta procurar na figura do líder ou na conformação social a racionalidade ordenadora e moralizante que falta em seu interior: "O que o membro fascista procura é a ilusão de controle para compensar seu sentimento de impotência" (BENJAMIN, 1977, 55).

Nessa situação, ocorreria uma "dessublimação" de conteúdos violentos do supereu. Pensemos: se a sublimação é caracterizada pelo desvio da finalidade pulsional na qual a agressividade não seria diretamente descarregada, mas desviada, a formação do supereu, enquanto uma instância psíquica, pode ser considerada como um desvio da meta pulsional agressiva que não foi descarregada na situação social do complexo de Édipo. Dessublimar o supereu, então, seria retomar as pulsões agressivas anteriormente sublimadas, levando-as à sua meta primeira de descarga pulsional direta em violência real.

Adorno resume o funcionamento metapsicológico do mais autoritário nomeando-o "falha da individuação", consequência de determinantes 
históricos do capitalismo. Assim, esta mera repetição da condição social hegemônica e esvaziamento da noção de indivíduo, inclusive em sentido metapsicológico, impossibilita uma análise verdadeiramente psicológica do tipo autoritário, o que fomenta uma pesquisa antropológica que diz mais sobre o ambiente cultural dos entrevistados do que sobre a própria subjetividade deles ${ }^{5}$. Se o preconceito não é um fenômeno gerado pela personalidade, mas tem a sua origem na sociedade, então podemos vislumbrar o motivo da psicanálise freudiana ser empregada na obra para fornecer explicações antropológicas e não precisamente psicológicas. Tratase da exposição de um momento de expansão capitalista para as esferas familiares e psíquicas que teria como que se "sedimentado" em formas típicas de expressão humana. Modo de expor o tipo autoritário como um retrato da socialização de indivíduos em um dado contexto, como formas reiteradas e sedimentadas de respostas psíquicas e humanas historicamente reificadas.

\section{Do capitalismo monopolista ao welfare state: Aspectos do novo radicalismo de direita}

Comparando os Estudos sobre a personalidade autoritária (pesquisa escrita ao longo de 1940 e publicada em 1950) e a conferência apresentada em 1967 intitulada Aspectos do novo radicalismo de direita, podemos dizer que Adorno produz diagnósticos críticos bem próximos nos dois textos, havendo apenas uma mudança na ênfase antropológica do autoritarismo. Ou seja, não haveria uma transformação de diagnóstico crítico, mas um realce em alguns traços do autoritarismo decorrentes de mudanças históricas do capitalismo. A análise geral de Adorno permanece a mesma, pois as condições de surgimento do autoritarismo perduram. Se há a manutenção ou a ampliação da pauperização e desigualdade capitalistas, então, haveria a persistência, manifesta ou latente, do autoritarismo.

Pretendemos demonstrar que, nos anos 1960, Adorno notou haver uma preponderância maior no aspecto destrutivo do autoritarismo, quando em comparação com o exposto nos anos 1940. Ou seja, em 1967, a ênfase deixa de ser encontrada no aspecto de pura adequação, como era ao longo de 1940, e passa a estar no desejo de destruição. A novidade é que se torna hegemônica, 20 anos depois, a manipulação do mal-estar, sofrimento e agressividade subjetivas a fim de alimentarem um desejo pela catástrofe.

Para fins de elucidação de tal diferenciação, lembremos que nos Estudos sobre a personalidade autoritária Adorno organizou uma síndrome geral do autoritário subdividida em uma série de tipos - que são organizações sistemáticas e recorrentes de sintomas autoritários exibidos 
em conjunto coeso. E como as condições de surgimento do autoritarismo se mantêm, a síndrome geral da antropologia formada sob o capitalismo permanece válida, havendo diferentes ênfases em determinados traços autoritários segundo as mudanças históricas do capitalismo. Dentre as características principais da personalidade autoritária ${ }^{6}$ elaboradas nos anos 1940, ressaltaremos duas delas, que serão retomadas por tipos específicos da síndrome: o convencionalismo, cujo representante seria o tipo convencional; e a destrutividade, que será representada pelos tipos alucinado e manipulador.

Nos anos 1940, a personalidade mais autoritária seria descrita como essencialmente convencionalista, adequada ao contexto social hegemônico, havendo poucos traços de produção subjetiva para a instauração do autoritarismo. A aceitação de padrões dominantes do status quo imperava, bem como a divisão social entre ingroup e outgroup, de modo que tal sujeito não seria particularmente violento. Adorno nos diz que, nesse tipo,

o preconceito aparentemente não cumpre uma função decisiva dentro da constituição psicológica dos indivíduos, sendo um meio de identificação fácil com o grupo ao qual pertencem ou ao qual desejam pertencer. Eles são preconceituosos no sentido específico do termo: assumindo os julgamentos correntes sobre os outros sem terem examinado a questão por si mesmos. Seu preconceito é uma "coisa natural", possivelmente "pré-consciente" e nem mesmo reconhecida pelos próprios sujeitos (ADORNO, 2019, 539).

Contudo, 20 anos depois, Adorno caminha para a formulação de uma retomada da agência interna para fins autoritários - ou ao menos a sensação de agência, num caminho para uma sociedade pós-repressiva hiperindividual neoliberal, algo que será bastante enfatizado nos tipos autoritários contemporâneos neoliberais. $O$ anseio de destrutividade exaltado como principal característica do novo radicalismo de direita em 1967 pode ser delineado, de um lado, pelo tipo alucinado. São geralmente pessoas que constroem um mundo interno ilusório, portando-se violentamente contra a realidade exterior, sendo semieruditos e tendo ideias conspiratórias. Portam-se como essencialmente frustrados diante das privações impostas pela realidade social, havendo um sentimento de impotência que os constitui. O vínculo com a dominação capitalista objetiva se mostra primordial: 
O padrão é encontrado em [pessoas] (...) cujo isolamento é socialmente reforçado por sua exclusão virtual do processo econômico de produção. Aqui encontramos (...) seguidores corriqueiros de agitadores, mesmo em períodos em que a propaganda racista está em baixa. A expressão frequentemente mal-usada "lunático extremo" tem certa validade em relação a eles: sua compulsão chegou ao estado de fanatismo (ADORNO, 2019, 557).

No texto de 1967, Adorno complementa sua descrição, dizendo que o lunático alimenta o desejo de colapso, vivendo um tipo de antecipação das consequências do capitalismo: seu medo do desemprego é objetivamente justificado pela provável substituição do trabalho humano por tecnologias, mas esse medo é falsamente projetado em grupos de minorias (que estariam supostamente roubando o seu emprego). Seu lado fanático fomenta um estado de alma apocalíptico, torcendo pela catástrofe social que justifique a instalação plena de uma sociedade fascista.

Se o alucinado ou lunático nutre fantasias de fim de mundo, por outro lado, Adorno ressalta a produção da destrutividade encontrada no tipo manipulador - o potencialmente mais perigoso. Ele é frio, processual, distanciado das emoções e vinculações humanas, inclinado à organização e ao uso da tecnologia para fins administrativos, preocupado que as coisas ou a economia funcionem, doa a quem doer, matando quem precisar matar. Ele não precisa nem odiar as suas vítimas, basta tratá-las como objetos e números. Há implicações destrutivas e cínicas em seu modo de pensar distanciado e dicotômico:

noções rígidas tornam-se fins e não meios e o mundo inteiro é subdividido em campos administrativos, vazios e esquemáticos. Há a quase completa falta de investimento objetal e de laços afetivos. (...) [É movido por] uma espécie de super-realismo compulsivo que trata tudo e todos como um objeto a ser utilizado e manipulado, apreendido pelos próprios padrões teóricos e práticos do sujeito. Os aspectos técnicos da vida e as coisas qua "instrumentos" são carregados de libido. A ênfase está em "fazer coisas", com ampla indiferença em relação ao conteúdo do que será feito. O padrão é encontrado em numerosos homens de negócio e também, em número cada vez maior, entre membros da ascendente classe gerencial e tecnológica que mantêm, no processo de produção, uma função entre o antigo tipo de proprietário e a aristocracia dos trabalhadores. (...) Seu modo 
organizacional de olhar para as coisas os predispõe a soluções autoritárias (ADORNO, 2019, 561-2).

Esse traço destrutivo já estava presente na síndrome autoritária descrita 20 anos antes, mas não seria visto, naquele momento, como a marca principal da personalidade autoritária. É como se historicamente houvesse sido fomentado de forma mais característica um anseio pela morte, a torcida de quanto pior melhor, como formas de atuação do autoritarismo. Nesse sentido, tanto o manipulador quanto o lunático espelhariam uma situação social em que já não seria mais suficiente a mera adequação a uma organização social hegemônica fascista latente, em que a utopia da transformação social teria malogrado. Assim, o novo radicalismo de direita pode ser visto como a confirmação da situação de colapso imposta pelo capitalismo, o qual está cada vez mais difícil de ser superado.

\section{Do welfare state ao neoliberalismo: recorrendo a interpretações adornianas}

Ao longo dos anos 1940, Adorno expôs como o tipo antropológico autoritário se limitava a se adequar a um contexto do capitalismo monopolista administrado por meio da fragilidade do eu, a externalização do supereu e a manipulação social do isso. Já em 1967, notamos que outra característica do autoritário passou a se mostrar preponderante: não mais a adequação à uma sociedade capitalista autoritária (com seus períodos mais latentes ou manifestos de expressão), mas sim o próprio desejo de colapso e destruição. Metapsicologicamente, tal desejo pode ser tomado como resultado da transformação do destino pulsional amedrontador e defensivo contra os males de uma sociedade já sem perspectivas de emancipação, antevendo as ruínas de crises inevitáveis do capitalismo após o bem-estar social.

Nesse sentido, ainda nos anos 1960, vemos se esboçar o caminho para a retomada de uma certa noção de agência subjetiva que fora, na fase monopolista do capitalismo, apaziguada, controlada e massificada para fins de pura adequação. A "recuperação" da noção de agência será de grande valia para pensarmos o tipo de autoritarismo vigente no neoliberalismo, onde a noção de sociedade repressiva (em seus moldes clássicos) fora ultrapassada, havendo um ímpeto individual pró-dominação atuando em cada indivíduo, sem necessidade de fortes e organizadas subjugações sociais para a manutenção capitalista. Afinal, o neoliberalismo pretende desintegrar a experiência de sociedade, passando a reorganizar a esfera do 
comum a partir da composição de indivíduos atomizados que se autogerenciam:

Como resultado de uma "afinidade eletiva" entre o desenvolvimento de um regime de acumulação pós-fordistafinanceirizado e a difusão de ideais românticos e estéticos de autenticidade pessoal, surgiu um "novo individualismo" em que a obediência disciplinar deu lugar ao empreendedorismo individual (...). Em vez de ser guiado (e limitado) por normas universais e relativamente fixas de racionalidade, este novo sujeito seria movido pela possibilidade (e pela exigência) de sustentar continuamente uma vida singular e autêntica, ou seja: uma vida autodescoberta e criada experimentalmente, emocionalmente comunicativa e adaptada de forma flexível às condições cambiantes de mercado (BUENO, 2020, 100).

Como se pode notar, portanto, a noção de um indivíduo que se contrapõe aos interesses sociais hegemônicos, como fora pensada por Adorno, não volta a ser recuperada de fato, sendo substituída por uma concepção individual não exatamente subjugada às normas sociais gerais, mas livre promovedora da dominação por si mesma.

Contudo, o próprio neoliberalismo impede que os sujeitos realizem efetivamente tal promessa de autonomia como autodeterminação e escolha individual. Para tanto, lembremos que, desde a década de 1970, o neoliberalismo não foi bem-sucedido em permitir que os sujeitos

pudessem exercer a sua capacidade de articular seus próprios interesses autônoma e racionalmente como prometido. (...) A sociedade proclama constantemente que qualquer um pode conseguir se apenas tentar o suficiente, ao mesmo tempo que reforça privilégios e aumenta a pressão em seus cidadãos sobrecarregados e exaustos. A constituição da subjetividade neoliberal implica tornar cada indivíduo cada vez mais responsável por seu próprio sucesso ou fracasso. Um dos epítetos mais contundentes de Trump é "perdedor". E isso, é claro, poderia ser dito para aumentar a pressão sobre os apoiadores de Trump, para colocar a culpa de seu próprio sucesso ou fracasso na presença de membros de um grupo estrangeiro e outsider (GANDESHA, 2008, 147).

Tal individualidade se encontra, então, em uma situação paradoxal de reativação, mas cuja realização não pode ser efetivamente cumprida. Ao transformar a possibilidade de sucesso em responsabilização individual, 
podemos dizer que algo da noção de indivíduo foi recuperada no neoliberalismo, mas sem haver as condições de realização autônoma da individualidade. Ou seja, a noção de indivíduo autônomo aproxima-se de uma ideologia quase impossível de ser realizada.

Dentre os pesquisadores adornianos que pretendem atualizar o conceito de autoritarismo no neoliberalismo, encontramos o canadense Samir Gandesha. Para ele, a recuperação ideológica da noção de indivíduo autônomo pode ser compreendida como um engajamento ativo pela identificação com o agressor, resultando em uma personalidade ainda mais autoritária: o supereu não precisa mais ser re-externalizado, projetado em um líder, mas o modelo do líder agressor é reinternalizado no eu. A dominação passa a ser ainda mais direta: o líder autoritário agora habita em cada um de nós. O supereu volta a ser internalizado, mas é constituído de modo superagressivo, impossível de ser satisfeito, o que culmina em uma culpa constante. Sobre a noção de "identificação com o agressor", Gandesha nos instrui:

Ferenczi formulou como "a identificação com o agressor" é uma resposta típica a condições de insegurança social e emocional generalizadas. Afinal, o capitalismo neoliberal envolve, como característica central, a destruição direta de toda uma rede de seguridade social por meio do que Harvey descreve como privatização e mercantilização, financeirização, gestão de crises e redistribuição da riqueza para os mais ricos. O efeito combinado desses quatro processos de neoliberalização é profundamente traumático, na medida em que aprofundam e aceleram a luta pela existência que sempre constituiu a insegurança que caracteriza o capitalismo em sua essência (GANDESHA, 2008, 160).

O sentimento de insegurança que decorre do descolamento do indivíduo da esfera do comum produz um modo de subjetivação típico no qual o supereu se mostra ainda mais severo, mas bastante desvinculado dos parâmetros e valorações gerais de condução social. Em momentos de crise (condição inevitável do capitalismo), não haveria como denunciar, demandar ou se revoltar contra as instâncias sociais, já que os autoritários neoliberais "introjetam a culpa do agressor pelas próprias condições da crise" (GANDESHA, 2008, 162). Se no neoliberalismo ocorre a terceirização da responsabilidade do social para o indivíduo, também são terceirizadas a culpa e a cobrança. 
Nesse sentido, vemos como Gandesha prepara o terreno para a compreensão dos "efeitos colaterais" da introjeção do objeto normativo no interior de si, qual seja, a produção da melancolia - ou depressão. Pensando no aspecto de identificação com o agressor, lembremos como Freud dá ênfase ao aspecto melancólico da identificação com a alteridade.

Voltemo-nos a $O$ eu e o isso, onde Freud descreve como o eu é formado por incorporações sucessivas de diferentes alteridades, identificações que eram anteriormente relações de objetos de amor que foram perdidos ou abandonados. A constituição do eu descreveria, então, a linhagem de apegos e perdas de alteridades que formariam seu caráter, resíduo melancólico de lutos de amores não resolvidos:

Se um tal objeto sexual deve ou tem de ser abandonado, não é raro sobrevir uma alteração do Eu, que é preciso descrever como estabelecimento do objeto no Eu, como sucede na melancolia (...). De todo modo, o processo é muito frequente, sobretudo nas primeiras fases do desenvolvimento, e pode possibilitar a concepção de que o caráter do Eu é um precipitado dos investimentos objetais abandonados, de que contém a história dessas escolhas de objeto. (FREUD, $1923 / 2011,36)$

Para tanto, Freud recorre à significação descrita em Luto e Melancolia, onde aborda como a melancolia seria uma reação psíquica à perda de um objeto investido libidinalmente (seja alguém, uma ideia, uma concepção de si mesmo) na qual o objeto perdido seria internalizado, constituindo parte de si mesmo. Tal internalização do objeto de amor mostra ser ambivalente, uma vez que toda a reação de agressão ou ódio contra tal objeto (e contra a sua perda) se transforma em uma agressão do eu contra si mesmo. Se no luto ocorre a internalização do objeto perdido, que pode, então, ser declarado morto, havendo uma finalização deste processo; na internalização melancólica ocorreria a manutenção da existência do objeto perdido, mantido vivo no interior do eu, o que configura uma situação sem fim. Por isso, a melancolia pode ser vista como uma produção desenfreada de ambivalência e ódio contra si mesmo: é agressão sem fim, desespero sem resolução.

Ao experimentar a frustração do impedimento de realização de si mesmo, o indivíduo neoliberal acaba relegado à sensação de impotência, precariedade e incerteza, o que levaria à melancolia, ou depressão: "O indivíduo depressivo marca o ponto em que a demanda para ser um empresário de si se torna subjetivamente problemática: quando a perspectiva de uma autorrealização autêntica se transforma em vazio e exaustão, quando a busca por autodeterminação termina em sentimentos 
de alienação." (BUENO, 2020, 100-1) O melancólico neoliberal finalmente percebe que a autonomia e a sensação de "agência" não passavam de uma ficção socioeconômica para a manutenção do próprio capitalismo que impede a autorrealização humana. Nota-se, então, como a dinâmica conflitual outrora social entre descontentamento e novas demandas "tornou-se uma tensão intrínseca na qual essas dimensões se confundem; uma tensão que, por isso mesmo, com frequência passa despercebida" (BUENO, 2020, 102) Nesse sentido de responsabilização individual e ausência de crítica social pela implosão da noção mesma de sociedade, operam os novos moldes do autoritarismo vigente sob as características de reindividualização por um supereu extrassevero (que leva a conflitos, tensões e cobranças internas excessivas) e sua contraposição melancólicodepressiva.

Visto isso, por mais que seja difícil correlacionarmos estritamente as descrições da síndrome autoritária que Adorno desenvolveu nos anos 1940 com as especificidades do sujeito autoritário neoliberal, podemos ao menos enfatizar alguns traços que nos auxiliariam na análise da antropologia atual. A ênfase na destruição - que deixa de ser vista como um medo ou desejo, como o era na época do welfare state, e passa a ser configurada como efetiva destruição interna por um supereu extrarrígido, identificado com o agressor - pode ser rastreada nas diferentes reativações do supereu. Faremos tal aproximação com a recorrência de duas das síndromes típicas descritas por Adorno: a autoritária e a rebelde/psicopata.

Descrevendo características da síndrome autoritária, Adorno nos mostra o aspecto irracional e desenfreado de sua faceta sádica, dotada de "uma categoria particular de supereu" (ADORNO, 2019, 544) ultrarrígido. Sendo típica de sujeitos que ocupam cargos administrativos de médio porte, eles se regozijam de "saberem que estão corretos" na condução de sua vida e na de seus subordinados. Sua faceta autoritária se utiliza da estereotipia para manifestar a compulsão para a obediência do supereu:

A estereotipia, nesta síndrome, não é apenas um meio de identificação social, mas tem uma função verdadeiramente "econômica" na própria psicologia do sujeito: ajuda a canalizar sua energia libidinal de acordo com as exigências de seu supereu extremamente rigoroso. Assim, a própria estereotipia tende a se tornar fortemente libidinizada e desempenha um papel importante na constituição interna do sujeito. Ele desenvolve traços de caráter profundamente "compulsivos", em parte pela regressão à fase de desenvolvimento sádico-anal. (ADORNO, 2019, 545) 
O seu ódio preconceituoso é projetado em figuras sociais que seriam vistas como perigosas por tentarem usurpar o controle, ao pretenderem modificar as normas hegemônicas de regulação vigente: sobre eles deve ser infringida a punição merecida. É assim que o tipo autoritário é potencialmente destrutivo em relação àqueles construídos como grupos mais "fracos", que recebem opiniões negativas, são moralmente condenáveis e para onde são direcionadas atitudes hostis e punições extrasseveras.

Já o rigorismo do supereu individual que se mostra desvinculado de normas sociais é descrito com bastante precisão pelo tipo rebelde, cuja manifestação extrema é encontrada na figura do psicopata. Sua principal marca é a insurreição contra autoridades externas, mas não de uma forma que promova a autonomia. Ao contrário, substituindo sua dependência por uma transferência negativa, seu "ódio irracional e cego a toda autoridade, com conotações fortemente destrutivas, [é] acompanhado por uma prontidão secreta para 'capitular' e dar as mãos ao forte 'odiado'." (ADORNO, 2019, 551)

Em um contexto que fomenta a execução do autoritarismo por cada indivíduo desvinculado de uma regulação social, é de se esperar que extremos sejam relacionados à aprovação de e atuação em milícias descritas por Adorno pela figura dos rackets, verdadeira "gangsterização" de parte da sociedade que é insuflada a fazer justiça com as próprias mãos. Procedendo conforme um "retrocesso à fantasia de onipotência da primeira infância" (ADORNO, 2019, 553), são propensos a "excessos tolerados" (que eram anteriormente puníveis, mas que passaram a ser socialmente "aprovados"), fazendo referências frequentes a violências corporais. Citando parte da descrição produzida anteriormente por Horkheimer, Adorno nos mostra que tal tipo é decorrente da desesperança de desempregados (ou economicamente desenraizados) que já desistiram de ser reabsorvidos pelo processo do trabalho, de forma que depositam seus ideais e sua vontade de agir "onde quer que possam agarrar alguma coisa." (HORKHEIMER, apud ADORNO, 2019, 552)

\section{Considerações finais}

Por mais que as manifestações de autoritarismo tenham se modificado desde os anos 1940 até hoje, ao lermos os Estudos sobre a personalidade autoritária, temos a impressão de que praticamente todos os seus traços são encontrados hoje em pessoas, movimentos e líderes de nosso país e afora. Contudo, por mais tentador que possa ser, temos que ter cuidado com o emprego de análises feitas nos anos 1940 ou 1960, nos 
Estados Unidos da América ou Europa, no contexto do Brasil em que vivemos. Deve-se levar em conta que a perspectiva da Teoria Crítica sozinha não é suficiente para abordar a situação atual brasileira, em especial por não ter investigado os traços decorrentes da experiência da colonização e da escravidão em nossa formação nacional. Contudo, isso não nos isenta de retomar as teorias adornianas a fim de elencar elementos de apoio para a análise contemporânea local.

Para lidar com tal sensação de imobilidade histórica, é nossa tarefa nos atermos às especificidades dos tipos de dominação ao longo do avanço do capitalismo, tentando antever não exatamente quais características autoritárias antigas devem ser descartadas, mas quais traços se constituem como tendências mais hegemônicas.

Contudo, lembremos que a noção de história na qual Adorno se baseia "é definida negativamente em termos de prevenção de uma catástrofe histórica" (GANDESHA, 2019, 2) enunciada, pois já anteriormente vivida. Em tal concepção negativa de história que marcha acelerada e novamente para a destruição (que deve ser ao mesmo tempo adiada), é inegável que a temática autoritária de ameaça à democracia e à humanidade é mais do que relevante. Assim, Adorno nos alerta para a possibilidade sempre iminente de que pseudodemocracias se tornem protofascismos, ou ainda, sociedades abertamente fascistas:

O que importa hoje não é tanto que as pessoas possam odiar suficientemente os judeus para iniciar um pogrom, mas que eles possam endossar um movimento que inclua o preconceito em sua plataforma. É muito mais importante averiguar os tipos de pessoas que podem estar dispostas a participar de movimentos ou apoiar governos que planejam exterminar os judeus, do que investigar a causa específica de problemas antissemitas em uma determinada área (ADORNO, 2016, 101). 


\section{Notas}

1 Parte do exposto aqui foi apresentado no $44^{\circ}$ Encontro Anual da ANPOCS, em 2020.

2 Pesquisadora de pós-doutorado em Filosofia na Universidade Federal do Espírito Santo (UFES), sob financiamento da Capes. Organizadora e tradutora dos Estudos sobre a personalidade autoritária.

3 Trata-se de "Remarks on The Authoritarian Personality" (ou "Observações sobre 'A Personalidade Autoritária", como foi traduzido recentemente para o português na Revista Trans/Form/Ação), um texto de Adorno que permaneceu inédito, tendo sido publicado somente no fim de 2016 . Originalmente seria um capítulo a integrar a obra The Authoritarian Personality.

${ }^{4}$ O capítulo de Horkheimer publicado originalmente nos Studien über Autorität und Familie é intitulado "Rascunhos Teóricos sobre Autoridade e Família: Parte Geral". Posteriormente, Horkheimer o publicou separadamente sob a forma de um ensaio, com algumas modificações, dando-Ihe o título de "Autoridade e família". É principalmente a este último que fazemos referência aqui.

${ }^{5}$ Podemos dizer que Adorno não só assume a teoria do fim do indivíduo, como também a utiliza para sustentar uma relação legítima entre pesquisa empírica e Teoria Crítica. É em mais de uma obra que o autor defende que aquilo que aparece como alienado nos sujeitos seria mais bem captado mediante métodos de sociologia empírica. O objetivo de pesquisa não seria exatamente desenvolver uma análise exaustiva e reflexiva dos sujeitos em sentido amplo, mas focar nas meras repetições feitas pelas pessoas de conteúdos já prontos, ou seja, nos elementos objetivados nos sujeitos. Nesse âmbito, a pesquisa quantitativa dos "Estudos sobre a personalidade autoritária" mostra ser a técnica mais adequada para a coleta de opiniões de pessoas que se submeteram quase completamente aos ditames da sociedade administrada: "A falta de liberdade dos métodos serve à liberdade dos homens, ao testemunhar sem palavras a falta de liberdade que impera." (ADORNO, 2001, 25) Nesse sentido, o método empírico de pesquisa não estaria escamoteando a situação antagônica entre o social e o individual, mas estaria revelando como tal antagonismo vem perdendo força por meio da massificação dos sujeitos. Estando submetido cegamente ao universal, as qualidades únicas de cada ser humano se perdem em simples reproduções estereotipadas, mesmo quando os sujeitos estariam opinando supostamente segundo seus próprios pontos de vista. 
${ }^{6}$ Adorno e seus companheiros de pesquisa chegaram a 9 características principais da personalidade de tipo autoritário expostas nas variáveis da famosa Escala $F$, descritas como sintomas que formam uma síndrome. Eis a lista das nove características: 1) convencionalismo, ou seja, a rígida aderência a valores da classe média e defesa do status quo, forma de identificação com grupos sociais considerados fortes e dominantes (modo de criar a ilusão de que se participa do poder); 2) submissão sem qualquer crítica a autoridades morais idealizadas como líderes; 3) agressão autoritária aos percebidos como mais "fracos" da sociedade (os out-groups), bem como a todos os símbolos e ideologias ligadas a eles, que recebem opiniões negativas, são moralmente condenáveis e para onde são direcionadas atitudes hostis e punições extrasseveras; 4) anti-intracepção que seria uma oposição a tudo o que seja subjetivo, imaginativo, introspectivo, até intelectual demais; 5) superstição e estereotipia; 6) insistência na divisão social em categorias como os fortes e fracos, dominadores e submissos; 7) destrutividade e cinismo - então tudo bem afirmar algo hoje e cinicamente afirmar o oposto amanhã, com a maior naturalidade, sem precisar se justificar; 8) projeções de desejos, medos e fantasias na alteridade; 9) e, por fim, preocupação exagerada em relação ao sexo.

\section{Referências bibliográficas}

ADORNO, T. W. Aspectos do novo radicalismo de direita. São Paulo: Editora Unesp, 2020.

ADORNO, T. W. Estudos sobre a personalidade autoritária. São Paulo: Editora Unesp, 2019.

ADORNO, T. W. Remarks on 'The Authoritarian Personality'. In. Platypus Review \#91, November 2016.

ADORNO, T. W. Sociología y investigación empírica. In. Epistemología y ciencias sociales. Frónesis Cátedra Universidad de Valencia: Madrid, 2001.

ADORNO, T. W., COSTA, V. H. F. Observações sobre 'A Personalidade Autoritária', de Adorno, Frenkel-Brunswik, Levinson e Sanford. Trans/Form/Ação, Marília, v. 44, n. 2, 345-384, Abr./Jun., 2021.

ADORNO, FRENKEL-BRUNSWIK, LEVINSON \& SANFORD. The Authoritarian Personality. Harper \& Brothers, Copyright American Jewish Committee, 1950.

BENJAMIN, J. The end of internalization: Adorno's social psychology. Telos, n. 32, 42-64, Summer, 1977. 
BUENO, A. ¿Qué viene después de la depresión? Ocho tesis sobre la crisis de la subjetividad neoliberal y sus implicancias políticas. Cuadernos de Teoría Social 6 (11), 2020, 95-120.

CHODOROW, N. The reproduction of mothering - psychoanalysis and the sociology of gender. Berkeley/Los Angeles/London: University of California Press, 1978.

COSTA, V. H. F. Resumo de The Authoritarian Personality. In. ADORNO, T. W. Estudos sobre a personalidade autoritária - São Paulo: Editora Unesp, 2019.

FREUD, S. Luto e melancolia. In. Obras completas volume 12. São Paulo: Companhia das Letras, 2010.

FREUD, S. O eu e o isso. In. Obras completas volume 16. São Paulo: Companhia das Letras, 2011.

FREUD, S. Psicologia das massas e análise do Eu. In. Obras completas volume 15. São Paulo: Companhia das Letras, 2011.

GANDESHA, S. Adorno, Ferenczi, and a new 'categorical imperative after Auschwitz'. International Forum of Psychoanalysis, 2019.

GANDESHA, S. Identifying with the agressor: From the Authoritarian to Neo-liberal Personality". Constelations, vol 25, Issue 1, March 2008, 147164. Disponível em <https://doi.org/10.1111/1467-8675.12338> (Acesso em 02 out. 2018).

GENEL, K. L'approche sociopsychologique de Horkheimer, entre Fromm et Adorno. Astérion. v. 7, ago. 2010. Disponível em <http://asterion.revues.org/1611>. (Acesso em 6 dez. 2017).

HORKHEIMER, M. Authority and the Family. In. Critical Theory - Selected Essays. New York: Continuum, 1982.

HORKHEIMER, M. \& ADORNO, T. W. Dialektik der Aufklärung: Philosophische Fragmente. Frankfurt am Main: Fischer, 1988.

HORKHEIMER, M. \& ADORNO, T. W. Dialética do esclarecimento: fragmentos filosóficos. Rio de Janeiro: Jorge Zahar Editor, 1985.

INSTITUT FÜR SOZIALFORSCHUNG (ed.). Studien über Autorität und Familie. Forschungsberichte aus dem Institut für Sozialforschung. Lüneburg: zu Klampen Verlag, 1987. 
MATOS, O. Os arcanos do inteiramente outro: a Escola de Frankfurt, a melancolia e a revolução. São Paulo: Ed. Brasiliense, 1995.

WHITEBOOK, J. Perversion and utopia - a study in psychoanalysis and Critical Theory. The MIT Press: Massachusetts, 1996. 